\title{
Hagar Espanha Gomes: múltiplos e inovadores movimentos acadêmicos e pedagógicos
}

\section{MOMENTO HISTÓRICO BRASILEIRO QUANDO DA CRIAÇÃO DO MESTRADO EM CIÊNCIA DA INFORMAÇÃO DO IBICT ${ }^{1}$}

Ao ser comemorado o cinquentenário da Ciência da Informação no Brasil e na América Latina, o editor-chefe de Ciência da Informação em Revista e professor da Universidade Federal de Alagoas (UFAL), Edivanio Duarte de Souza, me convidou para escrever um editorial comemorativo e homenagear uma das fundadoras do mestrado do Programa de PósGraduação em Ciência da Informação do Instituto Brasileiro de Informação em Ciência da Tecnologia (PPGCI/IBICT), que, por ser o pioneiro, completa 50 anos.

Hagar Espanha Gomes merece a nossa gratidão e reconhecimento, por ter sido uma das mentoras dessa iniciativa precursora no Brasil e presença permanente, mesmo depois de aposentada. Durante toda a sua vida, tem participado de atividades relevantes para o Programa, como a introdução de disciplinas inovadoras, orientações de dissertações e teses, bancas e eventos científicos, paralelamente às consultorias para o IBICT, que também contribuem com o ensino e a pesquisa.

A criação do mestrado de Ciência da Informação pelo antigo Instituto Brasileiro de Bibliografia e Documentação (IBBD), hoje IBICT, em 1970, foi um empreendimento ousado, quando o país ainda vivia numa ditadura desde 1964, fase em que a Ciência e Tecnologia e, consequentemente, a informação estavam vinculadas à segurança nacional, e a ênfase governamental era no planejamento (BRIQUET DE LEMOS, 1986). No Brasil, a ciência foi tardia e a informação não mereceu atenção nas políticas públicas, com apenas menções, inicialmente ao Sistema Nacional de Informação em Ciência e Tecnologia (SNIC, no $1^{\circ}$ Plano Nacional de Desenvolvimento (PND), de 1972/74 e nos seguintes. (BRASIL, 1971, 1976).

Sabemos que a criação da pós-graduação no IBBD foi um esforço coletivo, no qual pontificaram também Célia Zaher, bem como Lydia de Queiroz Sambaquy, fundadora e primeira diretora do IBBD, atual IBICT, uma vez que não podemos descolar o PPGCI do Instituto onde foi concebido e implantado. Lydia trouxe do antigo Departamento de Administração de Pessoal (DASP) a experiência do Serviço de Intercâmbio de Catalogação, implantado em 1942.

A criação do IBBD, em 1954, corresponde à década de institucionalização da pesquisa e pós-graduação em nosso país, uma vez que o Conselho Nacional de Pesquisa (CNPq), hoje Conselho Nacional de Desenvolvimento Científico e Tecnológico foi fundado em 15 de janeiro de 1951. No mesmo ano, a Coordenação de Aperfeiçoamento de Pessoal de Nível Superi-

\footnotetext{
${ }^{1}$ A citação somente ao IBICT é porque foi o Instituto que criou o Mestrado em Ciência da Informação, oferecido, com mandato acadêmico da UFRJ, e somente em 1982 foi assinado convênio com a Escola de Comunicação (ECO/UFRJ), mas, mesmo assim, praticamente sem a participação de professores da Universidade, o que de fato veio a ocorrer somente a partir do convênio de 2008.
} 
or (CAPES), órgão vinculado ao Ministério da Educação (MEC), alguns meses depois, em 15 de julho. A CAPES é responsável pelo acompanhamento, avaliação, apoio, expansão e consolidação da pós-graduação em território nacional (PINHEIRO, 1997).

Os aspectos históricos e a trajetória do mestrado foram estudados por alguns autores, mas, neste editorial, a fonte irradiadora de ideias é Hagar Espanha Gomes, de quem fui aluna e tenho convivido até os dias de hoje, num contínuo aprendizado. Como integrante da sétima turma, de 1977 e, portanto, alguém que vivenciou os anos do nascedouro do mestrado e até hoje, na qualidade de professora e pesquisadora, acompanha o seu desenvolvimento e evolução, espero acrescentar algo novo, tendo como leitmotiv a grande mestre Hagar Espanha Gomes.

\section{PARA COMPREENDER O CENÁRIO E CONCEPÇÃO DO MESTRADO EM CIÊNCIA DA INFOR- MAÇÃO}

O IBBD, desde o início, demonstrou a sua vocação para formação de recursos humanos quando, um ano após a sua fundação, foi implantado, por Lydia de Queiroz Sambaquy, o Curso de Especialização de Pesquisas Bibliográficas, em 1955, depois conhecido como Curso de Documentação Científica (CDC). O objetivo maior era formar profissionais para o Instituto, necessários principalmente para a produção de bibliografias especializadas, o catálogo coletivo nacional e o cadastro de pesquisas em andamento. Sua concepção foi mais um ato inovador, que pode ter sido inspirado em Paul Otlet (1868-1944), pois visava, também, a formação de documentalistas, daí ser aberto não somente a bibliotecários, mas a profissionais de diferentes áreas, interessados em documentação especializada. Foi a experiência de 15 anos de CDC a base de conhecimentos e experiência para a criação do mestrado.

Podemos fazer uma analogia com as atividades do Mundaneum de Paul Otlet, advogado de formação, dedicado à organização de documentos e ao processo de documentação, no final do século 19, e hoje considerado, por muitos autores, o fundador da Ciência da Informação e iniciador da gestão da informação. No entanto, na década de 1950, Otlet não era conhecido no cenário mundial da Biblioteconomia e Documentação, mas em nosso país foi exatamente Hagar Espanha Gomes quem introduziu as ideias de Otlet, nas suas aulas e na tese de livre docência "O Pensamento de Paul Otlet e os princípios do UNISIST", apresentada em 1975 (GOMES, 1975).

Foi Boyd Rayward, australiano biógrafo de Otlet, quem divulgou a sua obra no mundo, o que foi fundamental porque a língua original de Otlet era o francês, dificultando a sua propagação em países anglo-saxões, nos quais a Ciência da informação era e continua a ser mais desenvolvida, sobretudo nos Estados Unidos. Nesse país, somente em 1998 as ideias e obra de Otlet tornaram-se amplamente conhecidas, por meio da coletânea editada por Hann e Buckland, "Historical Studies in Information Science" e da qual fazem parte quatro textos especificamente dedicados a Paul Otlet.

O próprio título do IBBD, Instituto Brasileiro de Bibliografia e Documentação, poderia ter sido inspirado no Instituto Internacional de Bibliografia (IIB), fundado por Paul Otlet e Henri La Fontaine (1854-1943), em 1895, assim como os serviços desenvolvidos, principalmente as já mencionadas bibliografias, que marcaram tanto o IIB quanto o IBBD.

A constituição do mestrado em Ciência da Informação e as ideias norteadoras devem ser abordadas e descritas. 


\section{HAGAR ESPANHA GOMES E AS PRIMEIRAS IDEIAS E AÇÕES PARA A CRIAÇÃO DO MES- TRADO EM CIÊNCIA DA INFORMAÇÃO}

A formação do corpo docente do mestrado em Ciência da Informação seguiu os parâmetros de outros cursos de pós-graduação fundados no mesmo período, a participação de professores estrangeiros, pela inexistência ou pequeno número de doutores brasileiros no campo de conhecimento do curso. No caso do mestrado em questão, entre os professores estrangeiros, a maioria oriunda dos Estado Unidos, alguns deixaram marca mais profunda no mestrado porque, além de ministrarem aulas, orientaram dissertações até o ano de 1981. Entre esses professores, ressaltamos os seguintes: Frederick Wilfrid Lancaster (1933-2013), 34 orientações, Tefko Saracevic, 13 orientações, LaVahn Marie Overmyer, Bert Roy Boyce e Jack Mills (1918-2010), duas orientações cada, além de John Joseph Eyre, Ingetraut Dahlberg (1927-2017) e Suman Datta. Outros grandes nomes participaram do mestrado como conferencistas, entre os quais destacamos o físico e historiador da ciência Derek de Solla Price (1922-1983), da Yale University que, por ser o grande teórico e pai da Cientometria / Informetria, com vastíssima produção de mais de 300 obras, algumas muito lidas e estudadas no PPGCl e disciplinas importantes na grade curricular do mestrado, teve grande influência na formação brasileira, quiçá no destino do mestrado. (PINHEIRO; LOUREIRO, 1995).

Conversando com Hagar Espanha Gomes, falei da minha admiração pela pertinência e excelência dos professores estrangeiros convidados a participar do início do mestrado, e quis saber a quem devíamos tal escolha. Hagar explicou que a decisão foi de responsabilidade sobretudo de Celia Zaher e dela. No entanto, Hagar atribuiu principalmente a Jesse Shera (1903-1982), bibliotecário e grande teórico da área, cuja literatura era conhecida e estudada no Brasil que, na condição de Reitor da Western Reserve University, depois Case Western Reserve University, intermediou o processo e indicou alguns professores.

Por outro lado, a participação de professores brasileiros não deixou que perdêssemos a visão ou ficássemos de costas para o nosso próprio país. Entre esses professores, intelectuais do mais alto nível, ressalto Victor Vincent Valla (1937-2009), norte-americano naturalizado brasileiro, historiador de formação, mas com grande atuação em educação, principalmente a educação popular em favelas, comunidades. Valla ministrou aulas de desenvolvimento científico e tecnológico no Brasil, no mestrado do IBICT, juntamente com outros professores de história, como José Luiz Werneck da Silva (1932-1995) e Eduardo Silva.

Finalizo o reconhecimento aos grandes mestres, com Hilton Japiassu (1934-2015), filósofo e professor de Epistemologia, estudiosos da interdisciplinaridade. Considero Japiassu o grande responsável pela forte vertente filosófica que marca o ensino e pesquisa no PPGCI e que influenciou profundamente a minha vida acadêmica.

\section{MARCA E MARCOS DE HAGAR ESPANHA GOMES NO ENSINO E PESQUISA}

Hagar Espanha Gomes tem formação formal brasileira, mas o seu perfil intelectual é internacional, pelo vasto conhecimento de obras literárias estrangeiras e da produção em Biblioteconomia e Ciência da Informação no exterior, complementados por inúmeras viagens de estudos, participação em congressos e visitas técnicas no exterior.

Hagar Espanha Gomes reverencia os clássicos e os divulgou em aulas, bem como por meio de traduções e publicações de sua editora Calunga, da qual fomos sócias Maria de $\mathrm{Na-}$ zaré Freitas Pereira, a Nazinha, e eu, num aprendizado muito rico. A relevância dessas inicia- 
tivas deve-se ao tempo que levavam para chegar ao Brasil publicações estrangeiras e, neste caso, traduzidas para o português, tornando mais acessíveis e atingindo maior público. Entre os autores traduzidos e publicados destacamos os seguintes: D. J. Foskett, com "Informática e Ciência da Informação como disciplinas emergentes: implicações educacionais"; A. I Mikhailov, A. I. Chernyi e R. S. Gilyarevskyi em "Estrutura e principais propriedades da informação científica (a propósito do escopo da informática)"; e Jesse Shera, escrevendo "Sobre Biblioteconomia, Documentação e Ciência da Informação".

A segunda coletânea, denominada "A contribuição da Psicologia para o estudo dos usuários da informação técnico-científica", reuniu um texto de D. J. Foskett, sobre "Psicologia do usuário", de S. R. Ranganathan, sobre "Psicologia e natureza do trabalho de usuários"; e uma terceira pesquisa, a única de autoras brasileiras, Maria de Nazaré F. Pereira, Hagar E. Gomes, Lena Vania R. Pinheiro e Regina Maria S. de Oliveira, "A aplicação da técnica do incidente crítico em estudos de usuários de informação técnico-científica: uma abordagem comparativa".

Para a publicação de ambas as coletâneas Hagar conseguiu, gratuitamente, os direitos para edição em língua portuguesa de artigos de importantes periódicos como o Journal of Documentation, Journal of Librarianship, da UNESCO, Bulletin for Libraries, dos Proceedings da International Conference on Training for Information e também da Federação Internacional de Documentação (FID).

Da mesma forma, Hagar Espanha Gomes abraça os novos autores que vêm surgindo está sempre em movimento intelectual e a amplitude, diversidade e consistência de seus conhecimentos moldaram os seus princípios pedagógicos e seus ensinamentos.

Uma ideia original de Hagar foi a introdução da disciplina Comunicação Científica no mestrado, cujos conteúdos foram e continuam a ser muito importantes, como os canais de comunicação informais e formais, tendo como melhor exemplo os periódicos científicos e o respectivo processo de avalição pelos pares, os "referees". Sou professora de Comunicação Científica há alguns anos e nas minhas pesquisas sobre a Ciência da Informação constatei que essa disciplina foi introduzida em cursos do exterior especialmente com o surgimento da Internet/Web e a comunicação científica eletrônica. Assim, percebi que pelo fato de a estudarmos desde a institucionalização da ciência, nos séculos XVI e XVII, tivemos mais condições e bases histórica e teórica para compreender suas profundas transformações. Essas ideias germinaram e tiveram por fundamento a Sociologia da Ciência, o que também impulsionou a criação da revista Ciência da Informação, da qual Hagar coordenou a Comissão Editorial. (GOMES, 1996)

A juventude intelectual e a atualidade de suas iniciativas são comprovadas pelo "site" que coordena, Biblioteconomia, Informação \& Tecnologia da Informação (BITI), onde divulga pesquisas e estudos em classificação, terminologia, indexação e tesauro, entre outros.

Como aluna de Hagar, participante de suas aulas e projetos, resumiria as suas inúmeras qualidades pedagógicas em desafios, confiança, transparência e generosidade. Muitas vezes fui desafiada a desempenhar alguma atividade para qual não me considerava apta e era, de fato, inexperiente. Mas Hagar confiava e, por exemplo, nos entregava a missão de participar, em seu nome, da reunião de um projeto que coordenava, já que a substituíamos. Este aprendizado, amparado na transparência, repassando todas as fontes de informação e leituras, juntamente com seus ensinamentos e desafio, sempre foi muito enriquecedor. $E$ sua generosidade mesclada com a confiança, em termos de transmissão de fontes de informação e, muitas vezes, de empréstimos pessoais, também contribuiu muito. Para a mestra, 
o professor deveria repassar tudo aos alunos, não omitir nenhuma fonte, caso contrário, o bom aluno descobriria por si próprio.

Como colega de Hagar, constato que ela continuamente depurou os seus conhecimentos e intensificou as suas admiráveis qualidades.

Este ano, no dia 29 de setembro, Hagar Espanha Gomes completará 90 anos. Compartilho o meu júbilo com sua família, os filhos Maria Helena, Laura e Vinicius (mesmo nome do pai, marido e grande companheiro de Hagar, já falecido), a neta Macela e os bisnetos Luca, Carol e Pedro e com seus incontáveis alunos, colegas e professores. Salve, Hagar! Viva Hagar!

\section{REFERÊNCIAS}

BRASIL. Presidência da República. I Plano Básico de Desenvolvimento Científico e Tecnológico (1972/74). Brasília, 1971. Disponível em:

http://www.biblioteca.presidencia.gov.br/publicacoes-oficiais/catalogo/medici/i-pnd-72 74. Acesso em: 25 ago. 2020.

BRASIL. Presidência da República. II Plano Básico de Desenvolvimento Científico e Tecnológico - PBDCT (1975/79). Brasília, 1976. Disponível em: http://zenith.mast.br/MAST DOC/TEXTUAL/CNPq.T.2.2.010/CNPq.T.2.2.010 0021.pdf. Acesso em: 25 ago. 2020.

BRIQUET DE LEMOS, Antonio Agenor. Planejamento e coordenação da informação científica e tecnológica no Brasil. Ciência da Informação, Brasília, v. 15, n. 2, p. 107-115, jul./dez. 1986. Disponível em: http://revista.ibict.br/ciinf/article/view/231/231. Acesso em: 25 ago. 2020.

GOMES, Hagar Espanha (Org.). A contribuição da Psicologia para o estudo dos usuários da informação técnico-científica. Rio de Janeiro: Calunga, 1980.

GOMES, Hagar Espanha (Coord.). BITI - Biblioteconomia, Informação e Tecnologia da Informação. Rio de Janeiro, 2014. Disponível em: http://www.conexaorio.com/biti/index.htm. Acesso em: 25 ago. 2020.

GOMES, Hagar Espanha (Org.). Ciência da Informação ou Informática? Rio de Janeiro: Calunga, 1980.

GOMES, Hagar Espanha. Experiência do IBBD em programas de pós-graduação Revista Escola de Biblioteconomia da UFMG, Belo Horizonte, v. 3, n. 1, p. 13-26, mar. 1974. Disponível em: http://portaldeperiodicos.eci.ufmg.br/reb/. Acesso em: 25 ago. 2020.

GOMES, Hagar Espanha. O pensamento de Paul Otlet e os princípios do UNISIST. 1975. Tese (Livre-Docência) - Universidade Federal Fluminense, Niterói, 1975.

HAHN, Trudi B.; BUCKLAND, Michel (Eds.). Historical studies in information Science. Medford, NJ: ASIS, 1998. 326p. 
PINHEIRO, Lena Vania Ribeiro. Ciência da Informação entre sombra e luz: domínio epistemológico e campo interdisciplinar. Orientadora: Gilda Braga. 1997. 278 f. Tese (Doutorado em Comunicação e Cultura) - Escola de Comunicação, Universidade Federal do Rio de Janeiro, Rio de Janeiro, 1997. Disponível em:

https://ridi.ibict.br/bitstream/123456789/35/1/lenavaniapinheiro1997.pdf. Acesso em: 25 ago. 2020.

PINHEIRO, Lena Vania Ribeiro. Entrevista. Entrevistada: Hagar Espanha Gomes. Ciência da Informação, Brasília, v. 25, n. 3, 1996. Disponível em:

http://revista.ibict.br/ciinf/article/view/624/627. Acesso em: 25 ago. 2020.

PINHEIRO, Lena Vania Ribeiro; LOUREIRO, José Mauro Matheus. Traçados e limites da Ciência da Informação. Ciência da Informação, Brasília, v. 24, n. 1, p. 42-53, jan./abr. 1995. Disponível em: http://revista.ibict.br/ciinf/article/view/609/611. Acesso em: 25 ago. 2020.

\section{Lena Vania Ribeiro Pinheiro}

Doutora em Comunicação e Cultura (UFRJ)

Coordenação de Ensino e Pesquisa, Ciência e Tecnologia da Informação / Instituto Brasileiro de Informação em Ciência e Tecnologia (COEPE/IBICT)

lenavania@ibict.br 